\title{
Cadmium Intake as a Prognostic Factor in Endometrial Cancer: a Swedish Cohort-Based Study
}

$\underline{\text { Zoia Razumova }}^{1}$, Igor Govorov ${ }^{1,2}$, Ellinor Östensson ${ }^{1}$, Miriam Mints 1,3

1Division of Obstetrics and Gynaecology, Department of Women's and Children's Health, Karolinska Institutet, Stockholm, Sweden ${ }^{2}$ Institute of Perinatology and Paediatrics, Almazov National Medical Research Centre, St. Petersburg, Russia

${ }^{3}$ School of Medical Sciences, Faculty of Medicine and Health, Örebro University, Örebro, Sweden

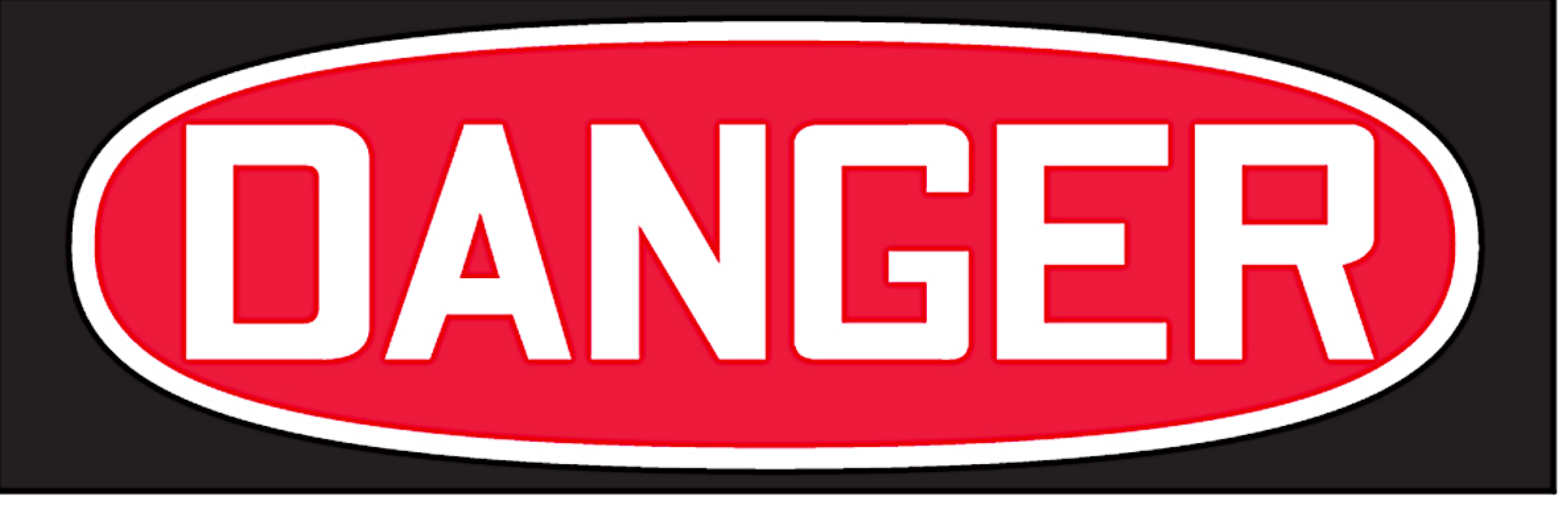

\section{CADMIUM CANCER HAZARD}

\section{Introduction}

Metalloendocrinology is a newly termed interdisciplinary field, which was established due to the importance of connections between inorganic chemicals and hormonal mechanisms. The role of cadmium in hormone-related tumours is an excellent example of this connection, as cadmium mimics oestrogen in the human body. Since endometrial cancer is hormone-related, it is well-suited for assessing the oestrogenic effects of cadmium.

\section{Aim}

To explore the role of dietary cadmium intake in the disease progression and survival of women with endometrial cancer.

\section{Methods}

This study is based on a large cohort of Swedish women $(n=416)$ with endometrial cancer. Dietary cadmium intake was estimated using a food frequency questionnaire, a comprehensive database on cadmium content, and average daily consumption of different food items. Estimated dietary cadmium intake was categorised into tertiles, which were analysed in relation to different tumour characteristics and clinical outcomes.

Cox proportional hazard models were used to estimate hazard ratios (HRs) and 95\% confidence intervals (Cls).

\section{Results}

Median daily dietary cadmium intake in the cohort was $13.1 \mu \mathrm{g}($ IQR $25 \%-75 \%=6.4)$ (Figure 1);

Figure 1. Dietary cadmium exposure in the study cohort ( $\mu \mathrm{g} / \mathrm{day})$

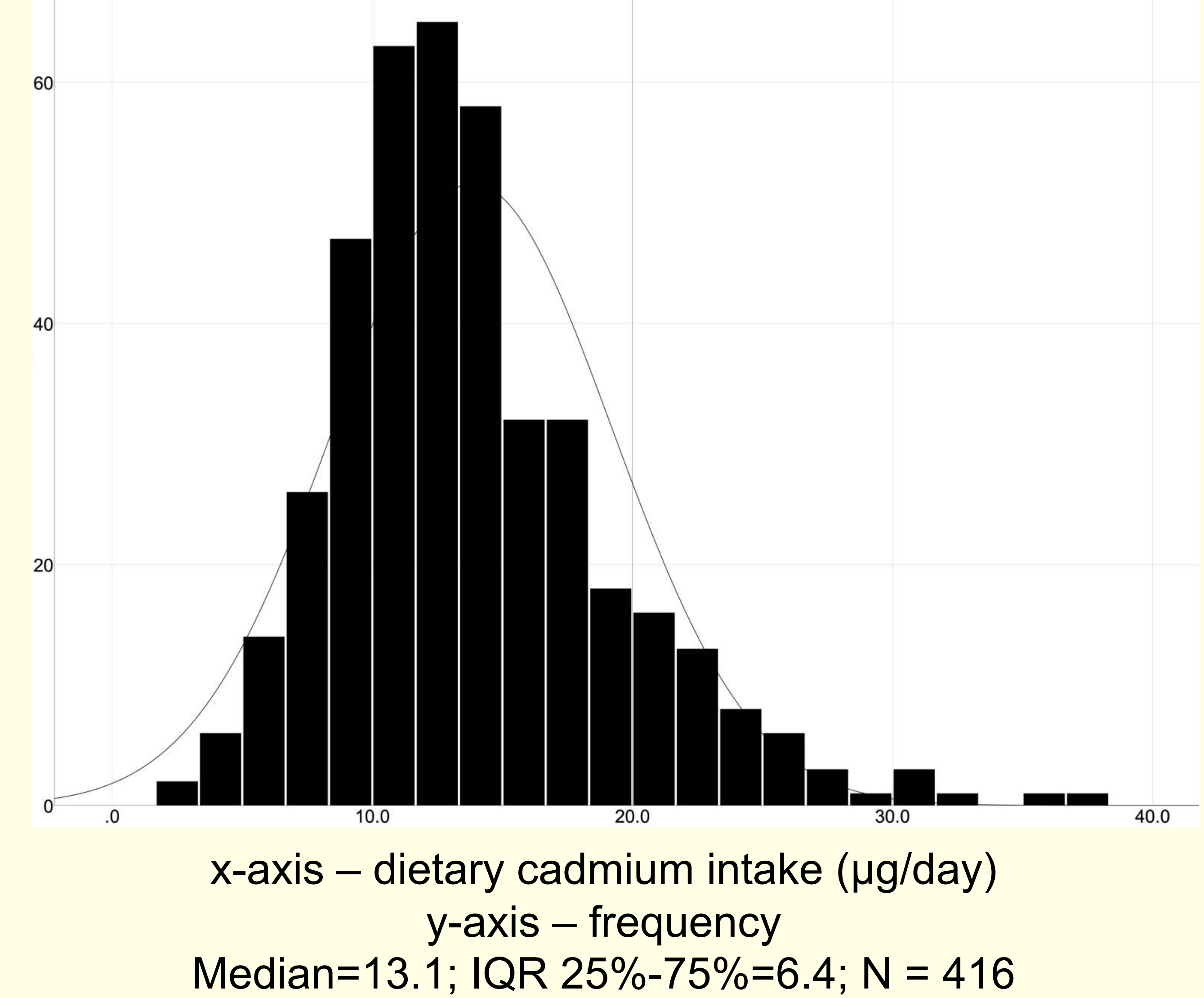

Cereal products and vegetables played a significant role;

$>$ High dietary cadmium intake ( $\mu \mathrm{g} /$ day) significantly decreased overall survival in the study cohort $(\mathrm{HR}=.956,95 \% \mathrm{Cl}=.914-1.001, \mathrm{p}=.05)$;

Dietary cadmium intake within the middle tertile (11.3-14.9 $\mu \mathrm{g} /$ day) was associated with decreased progression-free survival in comparison with the highest tertile $(\mathrm{HR}=2.429,95 \% \mathrm{Cl}=1.195-4.938$, $p=.014$ ).

\section{Conclusion}

$\checkmark$ Our results indicate that high dietary cadmium intake could be associated with poor prognosis and outcome in women with endometrial cancer.

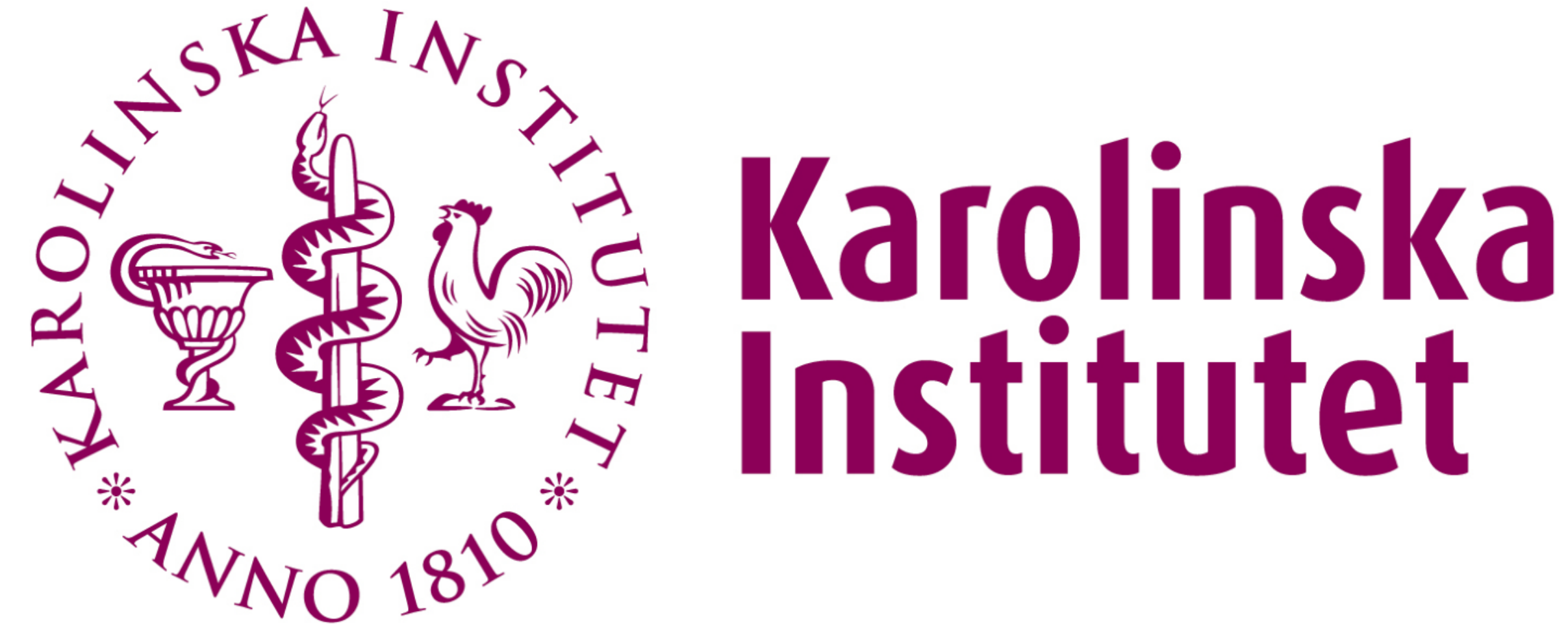

